\title{
Frequency of Various Risk Factors for Meconium Aspiration Syndrome
}

\author{
Muhammad Azeem Gulzar ${ }^{1} \quad$ Urwah Ehsan $^{2} \quad$ Muhammad Umair $^{3}$ \\ 1.House Officer, Nishtar Hospital Multan. \\ 2.House Officer, Bahawal Victoria Hospital, Bahawalpur. \\ 3.House Officer, Mayo Hospital Lahore.
}

\begin{abstract}
Objective: To study the frequency of various factor leading to meconium aspiration syndrome. Material \& Method: This present descriptive cross sectional study was carried out at Department of Pediatrics Medicine Nishtar Hospital Multan. for 6 months i.e. from October 8, 2017 to April 8, 2018. The non-probability, consecutive sampling technique was used. Newborns having staining of vocal cords and respiratory distress were included in this study. ABG and X ray Chest was done in all neonates. Factors like, Post-term pregnancy, IUGR, thick meconium, low APGAR score at 1 and 5 minutes were noted. All the collected data was entered and analyzed on SPSS version 23. Chi square and T test were used to check significant relation of risk factors with meconium aspiration syndrome. $\mathrm{P}$ value of 0,05 was consider significant. Results: Among total enrolled 150 babies, the mean age of babies was $37.37 \pm 18.96$ hours, the male to female ratio of the babies was $1.03: 1$. The mean maternal age was $28.85 \pm 6.602$ years. The thick meconium was observed in $89(59.33 \%)$ patients, $79(52.7 \%)$ patients went through vaginal delivery, postdate pregnancy was noted in $68(45.3 \%)$ patients, IUGR was observed in 52(34.7\%) patients and poor APGAR score at 1 min was noted in 79(52.7\%) patients. Conclusion: The observations of our study revealed that Meconium aspiration syndrome has significant relation with maternal age( $\mathrm{P}$ value 0.000$)$, postdated pregnancy(P Value 0.001), IUGR (P value 0.021), poor APGAR score at 5 minutes( $P$ value 0.034$)$, and thick meconium(P value 0.000$)$.
\end{abstract}

Keywords: Postdate, Meconium Aspiration, Syndrome, APGAR, Pregnancy

DOI: $10.7176 / \mathrm{JMPB} / 62-05$

Publication date: December $31^{\text {st }} 2019$

\section{Introduction}

Significant morbidity and mortality has been observed with meconium aspiration syndrome. ${ }^{1-3}$ One of the major causes of respiratory distress in term infants is meconium aspiration syndrome having incidence of 1.5 per 1000 live births. ${ }^{2}$ The passage of meconium in-utero predisposes an infant to meconium aspiration and has been observed in $10-20 \%$ of term deliveries and incidence is even higher in post-term infants $2^{\prime} 3^{\prime} 6 .^{2-4}$

Incidence of Meconium aspiration syndrome is lesser in pre-term deliveries. Recent literature showing reduction in mortality rate which is less than $15 \%$ appears to be associated with reduction in meconium aspiration syndrome owing to changes in obstetrical practices. ${ }^{2}$ The risk of meconium aspiration syndrome in an infant born with meconium stained amniotic fluid is influenced by birth asphyxia, quantity of meconium in amniotic fluid and presence of meconium in airways at delivery. From these risk factors asphyxia is the most important risk factor. ${ }^{2,5}$

Clinical features of meconium aspiration syndrome include respiratory distress within two hours of birth in an infant with meconium stained amniotic fluid, tachypnea and cyanosis. Chest auscultation shows inspiratory crepitations. ${ }^{6,7}$ Chest X-rays reveals variable atelectasis and patchy opacifications with areas of hyperinflation. Blood gases show hypoxemia often accompanied by hypercarbia. ${ }^{2}$

Complications of meconium aspiration syndrome include pneumonia, persistent pulmonary hypertension, interstitial emphysema and pneumothorax. ${ }^{8} 15-30 \%$ cases show pneumothorax'. There is a difference in outcome in patients with meconium aspiration syndrome in developing countries and those in developed countries and factors associated with poor outcome in developing countries include poor monitoring during labor and low APGAR scores'. ${ }^{9}$ There is limitation in assessing the outcome of meconium aspiration syndrome in developing countries these limitations are due to limited resources. ${ }^{1}$

In a study, neonates developing meconium aspiration syndrome secondary to meconium stained amniotic fluid were studied. The results of this study showed various risk factors for meconium aspiration syndrome which are: vaginal delivery (60\%) / C-section (40\%), post-maturity (48\%), Intra-uterine growth retardation (26\%), $1 \mathrm{~mm}$. low APGAR score (70\%), $5 \mathrm{~mm}$. low APGAR score (20\%), thick meconium $(69.7 \%) /$ thin meconium (36.4\%). Another study showed the incidence of these and some other risk factors leading to MAS in children with MSAF and showed similar results. ${ }^{3}$

As the incidence of meconium aspiration syndrome in developing countries is high and no significant and local data is available to assess various risk factors for meconium aspiration syndrome so the rationale of my study is to study the frequency of various risk factors for meconium aspiration in neonatal population so that a 
liaison can be made between obstetricians and pediatricians to reduce the incidence of meconium aspiration syndrome.

\section{Methodology}

A total number of 150 newborns presenting to Department of Paediatric Medicine Nishtar Hospital Multan with complaint of meconium staining was evaluated for the study. After explaining risks / benefits of the study and informed consent from parents, they were assessed by history and clinical examination. Sample size of 150 cases was calculated with 95\% confidence level, 7\% margin of error and taking expected percentage of low APGAR score at $5 \mathrm{mins}$ i.e. $20 \%$ (least among all) risk factor associated with meconium aspiration. Aspiration of meconium stained amniotic fluid before, during or after delivery resulting in respiratory distress assessed with respiratory rate more than $60 / \mathrm{mm}$, vocal cord staining seen by direct laryngoscopy, cord blood $\mathrm{pH} 7.16$ and $\mathrm{X}$ ray chest showing opacifications was labeled as meconium aspiration syndrome.

Intra-uterine Growth Retardation was labeled when birth weight less than 2.5SD of the normal as per WHO growth charts. Thick Meconium was judged by the color and texture of the meconium Green to dark-green and granular on visual inspection. The newborns with Meconium Stained body presenting in first 72 hours of life either gender included in the study. The newborns who had been associated congenital heart diseases assessed clinically with the help of auscultation, diaphragmatic hernia or any dysmorphism, was excluded. New borns not presenting with antenatal record were excluded from the study. ABG and X ray Chest was done in all neonates.

The data collection tool (Annexure- I hereby attached) was applied to finally selected patients to collect information regarding risk factors like, Post-term pregnancy, IUGR, thick meconium, low APGAR score at 1 and 5 minutes as per operational definition. Data was entered and analyzed by using computer program SPSS10. Descriptive statistics was applied to calculate mean and standard deviation for maternal age. Frequencies and percentages was calculated for risk factors like Post-term pregnancy, IUGR, thick meconium, low APGAR score at 1 and 5 minutes. Data was stratified for maternal age, mode of delivery (c/section/vaginal) to deal with effect modifiers. Post-stratification, chi-square test was applied and $p$-value $\leq 0.05$ was considered significant.

\section{Results}

Among total 150 patients enrolled in this study the mean age of the babies was $37.37 \pm 18.96$ hours with minimum and maximum ages of $6 \& 72$ hours respectively. In our study $76(50.67 \%)$ babies were male and $74(49.33 \%)$ babies were females. The male to female ratio of the babies was 1.03:1. The study results showed that the mean value maternal age was $28.85 \pm 6.602$ years with minimum and maximum ages of $18 \& 40$ years respectively (Table-1).

In this study $79(52.7 \%)$ patients went through vaginal delivery and 71(47.3\%) patients went through CS. In this study the postdate pregnancy was noted in $68(45.3 \%)$ patients. Out of 150 patients the IUGR was observed in 52(34.7\%) patients and it was not observed in 98(65.3\%) patients. Out of 150 patients the poor APGAR score at $1 \mathrm{~min}$ was noted in 79(52.7\%) patients and good APGAR score at $1 \mathrm{~min}$ was noted in 71(47.3\%) patients. The study results showed that the poor APGAR score at 5 min was noted in 69(46\%) patients and good APGAR score at 5 min was noted in $81(54 \%)$ patients. According to our study results the thick meconium was observed in $89(59.33 \%)$ patients and it was not observed in 61(40.67\%) patients (Table-2).

In our study statistically insignificant association was found between meconium aspiration syndrome and poor APGAR score at 1 , mode of delivery i.e vaginal or caesarean section and baby gender i.e male or female with $P$ value $0.734,0.821$ and 0.892 respectively.

In this study statistically significant association was found between meconium aspiration syndrome and poor APGAR score at 5 minutes, maternal age , post dated pregnancy, IUGR, and thick meconium with P value $0.034,0.000,0.001,0,021$ and 0.000 respectively.

Table-1: Demographic variables

\begin{tabular}{|c|c|c|c|}
\hline Characteristics & Mean & SD & P Value \\
\hline Age & 37.37 & 18.96 & 0.673 \\
\hline Maternal age & 28.85 & 6.602 & 0.000 \\
\hline \multicolumn{2}{|c|}{ Gender } & 0.892 \\
\hline Male & 76 & $50.67 \%$ & \\
\hline
\end{tabular}


Table-2: Frequency (Percentages) of Meconium Aspiration Syndrome

\begin{tabular}{|c|c|c|c|}
\hline Characteristics & Frequency & Percentages $\%$ & P Value \\
\hline \multicolumn{3}{|c|}{ Mode of delivery } & \\
\hline Vaginal & 79 & $52.7 \%$ & \multirow[t]{2}{*}{0.821} \\
\hline Cesarean & 71 & $47.3 \%$ & \\
\hline \multicolumn{3}{|c|}{ Postdate pregnancy } & \\
\hline Yes & 68 & $45.3 \%$ & \multirow{2}{*}{0.001} \\
\hline No & 82 & $54.7 \%$ & \\
\hline \multicolumn{3}{|c|}{ IUGR } & \multirow{3}{*}{0.021} \\
\hline Yes & 52 & $34.7 \%$ & \\
\hline No & 98 & $65.3 \%$ & \\
\hline \multicolumn{3}{|c|}{ Poor APGAR at $1 \mathrm{~min}$} & \multirow{3}{*}{0.734} \\
\hline Yes & 79 & $52.7 \%$ & \\
\hline No & 71 & $47.3 \%$ & \\
\hline \multicolumn{3}{|c|}{ Poor APGAR at 5 min } & \multirow{3}{*}{0.034} \\
\hline Yes & 69 & $46.0 \%$ & \\
\hline No & 81 & $54.0 \%$ & \\
\hline \multicolumn{3}{|c|}{ Thick Meconium } & \multirow{3}{*}{0.000} \\
\hline Yes & 89 & $59.33 \%$ & \\
\hline No & 61 & $40.67 \%$ & \\
\hline
\end{tabular}

\section{Discussion:}

This present descriptive cross sectional study was conducted at Pediatrics Unit-I Services Hospital Lahore to study the frequency of various factor leading to MAS. MAS is a common cause of lung disease in neonates. Cause of MAS is inhalation of thick meconium. Most of time it is due to hypoxia of fetus which can increased the peristaltic movement, gasping reflux and relaxation of anal sphincters. ${ }^{10}$ Meconium passage occurs in up to $20 \%$ of fullterm gestations and can occur in more than $35 \%$ of pregnancies continuing beyond 42 weeks' gestation. ${ }^{11-16}$

In our study $79(52.7 \%)$ patients went through vaginal delivery and 71(47.3\%) patients went through CS, the postdate pregnancy was noted in $68(45.3 \%)$ patients, the IUGR was observed in $52(34.7 \%)$ patients, the poor APGAR score at $1 \mathrm{~min}$ was noted in $79(52.7 \%)$ patients and poor APGAR score at 5 min was noted in $69(46 \%)$ patients. In this study the thick meconium was observed in $89(59.33 \%)$ patients. Maternal age and mode of delivery showed insignificant difference with factors. Incidence of MAS occurs in long time periode due to less cases of post term deliveries, close monitoring and management of fetal heart rate and reduction in the low APGAR score births. ${ }^{17}$

In a study, neonates developing MAS secondary to meconium stained amniotic fluid were studied. The results of this study showed various risk factors for MAS which are: vaginal delivery $(60 \%) / \mathrm{C}$-section $(40 \%)$, post-maturiy (48\%), Intra-uterine growth retardation (26\%), $1 \mathrm{~mm}$. low APGAR score (70\%), $5 \mathrm{~mm}$. low APGAR score $(20 \%)$, thick meconium $(69.7 \%)$ / thin meconium $(36.4 \%)$. Another study showed the incidence of these and some other risk factors leading to MAS in children with MSAF and showed similar results. ${ }^{3}$

At 41 weeks or beyond these weeks elective induction of labour found to be highly associated with low rate of MAS and minimal perinatal mortality and morbidity when compared with expectant management. ${ }^{18}$

A study by Uzma Firdaus et a ${ }^{19}$ reported $9.8 \%$ incidence of MSAF and $1.8 \%$ of MAS. He reported that fetal respiratory distress and low APGAR score are the main risk factors of MAS, maternal risk factors are not prominent. In the study by swain et al, the incidence of MSAF was $13.97 \%$ and that of MAS was $8.57 \%{ }^{20}$ In the study by Manganaro et al no significant difference in parity, maternal age, gestational age, metabolic acidemia, sex, low APGAR score at 1 minute and 5 minute and need for endotracheal intubation was observed between both groups MSAF and non-MSAF infants. ${ }^{21}$

Bhat RY et $\mathrm{al}^{22}$ however found thick meconium as the only significant factor contributing to MAS. Another work by Khazardoost et $\mathrm{al}^{23}$ did not find the role any maternal factors in predicting the progression to MAS. In a previous study conducted by Usta et al study ${ }^{24}$ it was reported late maturity not a risk factor of MAS. Conclusion of his study favors the concept that incidence of meconium aspiration occurs in normaly mature infants that leads the infants fetal compromise and MAS. Some studies demonstrated that the presence of fetal compromise like low Apgar score, ${ }^{25-27}$ abnormal heart rhythm ${ }^{28,29}$ and cesarean deliveries enhance the chances of MAS in infants. and of MAS in the meconium-stained infant. ${ }^{30}$

\section{Conclusion}

The observations of our study revealed that Meconium aspiration syndrome has significant relation with 
maternal age(P value 0.000), postdated pregnancy(P Value 0.001), IUGR (P value 0.021), poor APGAR score at 5 minutes( $\mathrm{P}$ value 0.034$)$, and thick meconium ( $\mathrm{P}$ value 0.000$)$.

\section{References}

1. Padmanabhan V, Siefert K, Ransom S, Johnson T, Pinkerton J, Anderson L, et al. Maternal bisphenol-A levels at delivery: a looming problem? Journal of Perinatology. 2008;28(4):258-63.

2. Francoual J, Lindenbaum A, Benattar C, Dehan M, Cohen H, Leluc R. Importance of simultaneous determination of coproporphyrin and hemoglobin in contaminated amniotic fluid. Clinical chemistry. 1986;32(5):877-8.

3. Choi W, Jeong H, Choi S-J, Oh S-Y, Kim J-S, Roh C-R, et al. Risk factors differentiating mild/moderate from severe meconium aspiration syndrome in meconium-stained neonates. Obstetrics \& gynecology science. 2015;58(1):24-31.

4. Bacsik R. Meconium aspiration syndrome. Pediatric clinics of North America. 1977;24(3):463.

5. Wiswell TE, Tuggle JM, Turner BS. Meconium aspiration syndrome: have we made a difference? Pediatrics. 1990;85(5):715-21.

6. Singh B, Clark R, Powers R, Spitzer A. Meconium aspiration syndrome remains a significant problem in the NICU: outcomes and treatment patterns in term neonates admitted for intensive care during a ten-year period. Journal of Perinatology. 2009;29(7):497-503.

7. Dargaville PA, Copnell B. The epidemiology of meconium aspiration syndrome: incidence, risk factors, therapies, and outcome. Pediatrics. 2006;117(5):1712-21.

8. Findlay RD, Taeusch HW, Walther FJ. Surfactant replacement therapy for meconium aspiration syndrome. Pediatrics. 1996;97(1):48-52.

9. Janssen DJ, Carnielli VP, Cogo P, Bohlin K, Hamvas A, Luijendijk IH, et al. Surfactant phosphatidylcholine metabolism in neonates with meconium aspiration syndrome. The Journal of pediatrics. 2006;149(5):634-9.

10. Bacsik RD. Meconium aspiration syndrome. Pediatric Clinics of North America. 1977;24(3):463-79.

11. Maymon E, Chaim W, Furman B, Ghezzi F, Vardi IS, Mazor M. Meconium stained amniotic fluid in very low risk pregnancies at term gestation. European Journal of Obstetrics \& Gynecology and Reproductive Biology. 1998;80(2):169-73.

12. Matthews TG, Warshaw JB. Relevance of the gestational age distribution of meconium passage in utero. Pediatrics. 1979;64(1):30-1.

13. Ostrea EM, Naqvi M. The influence of gestational age on the ability of the fetus to pass meconium in utero: clinical implications. Acta obstetricia et gynecologica Scandinavica. 1982;61(3):275-7.

14. Eden RD, Seifert LS, Winegar A, Spellacy WN. Perinatal characteristics of uncomplicated postdate pregnancies. Obstetrics \& Gynecology. 1987;69(3):296-9.

15. Steer P, Eigbe F, Lissauer T, Beard R. Interrelationships among abnormal cardiotocograms in labor, meconium staining of the amniotic fluid, arterial cord blood $\mathrm{pH}$, and Apgar scores. Obstetrics \& Gynecology. 1989;74(5):715-21.

16. Usher RH, Boyd ME, McLean FH, Kramer MS. Assessment of fetal risk in postdate pregnancies. American journal of obstetrics and gynecology. 1988;158(2):259-64.

17. Swarnam K, Soraisham AS, Sivanandan S. Advances in the management of meconium aspiration syndrome. International journal of pediatrics. 2011;2012.

18. Hussain AA, Yakoob MY, Imdad A, Bhutta ZA. Elective induction for pregnancies at or beyond 41 weeks of gestation and its impact on stillbirths: a systematic review with meta-analysis. BMC Public Health. 2011;11(3):S5.

19. Firdaus U, Ali SM. Maternal and neonatal factors associated with meconium stained amniotic fluid. Current Pediatrics. 2013;17(1).

20. Whitfield JM, Charsha DS, Chiruvolu A, editors. Prevention of meconium aspiration syndrome: an update and the Baylor experience. Baylor University Medical Center Proceedings; 2009: Baylor University Medical Center.

21. Gupta V, Bhatia B, Mishra O. Meconium stained amniotic fluid: antenatal, intrapartum and neonatal attributes. Indian pediatrics. 1996;33:293-8.

22. Bhat R, Rao A. Meconium-stained amniotic fluid and meconium aspiration syndrome: a prospective study. Annals of tropical paediatrics. 2008;28(3):199-203.

23. Khazardoost S, Hantoushzadeh S, Khooshideh M, Borna S. Risk factors for meconium aspiration in meconium stained amniotic fluid. Journal of Obstetrics and Gynaecology. 2007;27(6):577-9.

24. Usta IM, Mercer BM, Sibai BM. Risk factors for meconium aspiration syndrome. Obstetrics \& Gynecology. 1995;86(2):230-4.

25. Sriram S, Wall SN, Khoshnood B, Singh JK, Hsieh H-L, Lee K-S. Racial disparity in meconium-stained amniotic fluid and meconium aspiration syndrome in the United States, 1989-2000. Obstetrics \& 
Gynecology. 2003;102(6):1262-8.

26. Peng TC, Gutcher GR, Van Dorsten JP. A selective aggressive approach to the neonate exposed to meconium-stained amniotic fluid. American journal of obstetrics and gynecology. 1996;175(2):296-303.

27. Alexander GR, Hulsey TC, Robillard P-Y, De Caunes F, Papiernik E. Determinants of meconium-stained amniotic fluid in term pregnancies. Journal of perinatology: official journal of the California Perinatal Association. 1993;14(4):259-63.

28. Yoder BA, Kirsch EA, Barth Jr WH, Gordon MC. Changing obstetric practices associated with decreasing incidence of meconium aspiration syndrome. Obstetrics \& Gynecology. 2002;99(5, Part 1):731-9.

29. Paz Y, Solt I, Zimmer EZ. Variables associated with meconium aspiration syndrome in labors with thick meconium. European Journal of Obstetrics \& Gynecology and Reproductive Biology. 2001;94(1):27-30.

30. Hernández C, Little BB, Dax JS, Gilstrap LC, Rosenfeld CR. Prediction of the severity of meconium aspiration syndrome. American journal of obstetrics and gynecology. 1993;169(1):61-70. 